Çukurova Üniversitesi Mühendislik Mimarlık Fakültesi Dergisi, 34(4), ss. 21-28, Aralık 2019

Çukurova University Journal of the Faculty of Engineering and Architecture, 34(4), pp. 21-28, December 2019

\title{
Birinci Mertebe Kayma Deformasyon Teorisine Dayalı FD Düz Eksenli Kirişlerin Serbest Titreşim Analizi
}

\author{
Timuçin Alp ASLAN ${ }^{* 1}$, Ahmad Reshad NOORI², Beytullah TEMEL ${ }^{1}$ \\ ${ }^{1}$ Çukurova Üniversitesi, Mühendislik Fakültesi, İnşaat Mühendisliği Bölümü, Adana \\ ${ }^{2}$ İstanbul Gelişim Üniversitesi, Mühendislik-Mimarlık Fakültesi, İnşaat Mühendisliği Bölümü, \\ Istanbul
}

Geliş tarihi: 19.09.2019Ｋabul tarihi: 20.12.2019

\section{$\ddot{O} z$}

$\mathrm{Bu}$ çalışmada, birinci mertebe kayma deformasyon teorisine dayalı doğru eksenli fonksiyonel derecelenmiş (FD) malzemeli kirişlerin serbest titreşim özellikleri incelenmiştir. Malzeme özelliklerinin sadece kiriş kalınlığı boyunca değiştiği kabulü yapılmıştır. Malzeme değişim katsayısının, uzunluk/kalınlık oranlarının ve sınır koşullarının kirişlerin serbest titreşim davranışı üzerindeki etkileri de parametrik olarak incelenmiştir. Bu kirişlerin serbest titreşim davranışını idare eden hareket denklemleri, Timoshenko kiriş varsayımına dayalı minimum toplam enerji ilkesi kullanılarak elde edilmiştir. Kanonik halde elde edilen bu adi diferansiyel denklemler Tamamlayıcı Fonksiyonlar Yöntemi (TFY) ile sayısal olarak çözülmüştür. Hesaplanan doğal titreşim frekansları, literatürdeki mevcut çalışmaların sonuçları ile karşılaştırılmış ve bunlarla uyum içerisinde olduğu gösterilmiştir.

Anahtar Kelimeler: Fonksiyonel derecelenmiş malzeme, Tamamlayıcı fonksiyonlar yöntemi, Serbest titreşim analizi

\section{Free Vibration Analysis of FG Straight-Axis Beams Based on the First-Order Shear Deformation Theory}

\begin{abstract}
In this work, the free vibration characteristics of functionally graded (FG) beams with straight-axis are investigated based on the first-order shear deformation theory (FSDT). It is assumed that the material properties change only through the thickness of the beam. The effects of the coefficient of variation, length/thickness ratios and boundary conditions on the free vibration behavior of the beams are also examined in a parametric manner. The equations of motion, governing the free vibration behavior of these beams are obtained using the principle of minimum total energy based on the Timoshenko's beam assumption. These ordinary differential equations (ODEs) obtained in the canonical form are solved numerically by the Complementary Functions Method (CFM). The calculated natural vibration frequencies are compared with the results of the existing studies in the literature and shown to be in agreement with them.
\end{abstract}

Keywords: Functionally graded materials, Complementary functions method, Free vibration analysis

*Sorumlu (Corresponding author) yazar: Timuçin Alp ASLAN, taslan@cu.edu.tr 


\section{GíRiş}

FD kirişlerde malzeme özellikleri, belli bir fonksiyona bağlı olarak kirişin kalınlığı veya ekseni boyunca, yavaşça veya kademeli olarak değiştirilmesiyle elde edilmektedir. Bu tür kirişler çeşitli mühendislik uygulamalarında yapısal elemanlar olarak kullanılmaktadır. Servis ömrü boyunca çeşitli statik ve dinamik yüklerin etkisinde kalabilmektedir. $\mathrm{Bu}$ nedenle FD malzemeli kirişlerin statik ve dinamik davranışlarının incelenmesi yapı mekaniğinin en önemli araştırma konularından biridir.

Aydoğdu ve Taşkın [1], basit mesnetli FD malzemeli kirişin serbest titreşimini çeşitli yüksek mertebe ve klasik kiriş teorilerini kullanarak incelemişlerdir. Hareket denklemlerini Hamilton prensibi ile elde edip, Navier yöntemi yardımıyla kirişin doğal frekanslarını bulmuşlardır. Li [2], FD kirişlerin statik ve dinamik davranışlarını analiz etmek için yeni bir birleşik yaklaşım ileri sürmüştür. Dördüncü dereceden kısmi diferansiyel denklemi türetmiş ve problemin fiziksel niceliklerini bu denklemin çözümüyle elde etmiştir. Kirişin frekans denklemini belirleyerek serbest titreşim analizini yapmıştır. Sina ve arkadaşları [3], birinci mertebe kayma deformasyon yaklaşımından farklı yeni bir kiriş teorisi kullanarak, FD kirişlerin serbest titreşim frekanslarını elde etmiştir. Kirişte yanal normal gerilmelerin sıfır olduğunu varsayarak Hamilton prensipleri yardımıyla hareket denklemlerini türetmiştir. Analitik yöntemden faydalanarak serbest titreşim analizini idare eden diferansiyel denklemi çözmüştür. Çeşitli sınır koşulları ve farklı kiriş teorileri arasında karşılaştırılmalar yapmıştır. Şimşek [4], hareketli bir kütle ile yüklenebilir basit mesnetli FD kirişin titreşim davranışını Euler-Bernoulli, Timoshenko ve üçüncü mertebe kayma deformasyon teorilerinden faydalanarak incelemiştir. Kirişin malzeme özelliklerinin kalınlık boyunca sürekli olarak değiştiğini varsaymıştır.

Alshorbagy ve ark. [5], malzeme değişim katsayısına dayalı olarak, FD kirişin dinamik karakteristiği üzerine çalışmışlardır. Farklı malzeme dağılımları, çeşitli kalınlık oranları ve
Sınır şartlarının kirişin dinamik karakteristiği üzerindeki etkilerine ait sayısal sonuçları çizelge ve grafik formunda sunmuşlardır. Ayrıca bu etkilerin kirişin dinamik davranışı üzerinde çok önemli rol oynadığını vurgulamışlardır. Sanjay ve arkadaşları [6], kirişlerin serbest titreşim analizini araştırmak için biri Euler-Bernoulli kiriş teorisine dayanan, diğeri Timoshenko kiriş teorisine dayanan iki ayrı sonlu eleman formülasyonu geliştirmişlerdir. Sonlu elemanlar yönteminin denklem sistemini elde etmek için Virtüel iş prensibini kullanmışlardır. Thai ve Vo [7], literatürde bulunan çeşitli yüksek mertebe kayma deformasyonu teorilerini FD kirişlerin serbest titreşim analizlerinde kullanmışlardır. Göz önüne alınan teorilerde, kiriş yüksekliği boyunca kayma şekil değiştirmesinin yüksek mertebe değişimi dikkate alınmaktadır. Pradhan ve Chakraverty [8], analizlerini klasik ve birinci mertebeden kayma deformasyon kiriş teorilerine dayandırmaktadırlar. Kalınlık boyunca malzeme özellikleri değişen kiriş kesitlerinin yer değiştirme bileşenlerini gösteren deneme fonksiyonları, basit cebirsel polinom formlarında ifade edilmiştir. Temel denklemleri Rayleigh-Ritz metodu ile elde etmişlerdir.

Nguyen ve arkadaşları [9], eksenel yüklü kirişlerin statik ve serbest titreşimleri için birinci mertebe kayma deformasyon teorisini geliştirmişlerdir. Bu teoride, geliştirilen enine kayma rijitliğini, düzlem içi gerilme ve denge denkleminden elde etmiş ve böylece ilişkili kayma düzeltme faktörünü daha sonra analitik olarak elde etmişlerdir. Hareket denklemleri Hamilton ilkesinden türetilmiştir. Analitik çözümlerini, basit mesnetli FD kirişler için sunmuşlardır. Su ve arkadaşları [10] ise, FD kirişlerin serbest titreşim davranışını araştırmak için dinamik rijitlik matrisini geliştirmişlerdir. Serbest titreşimler için, Hamilton ilkesi yardımıyla hareket ve doğal sınır koşullarının temel denklemlerini türetmişler ve harmonik salınım için diferansiyel denklemleri kapalı formda çözmüşlerdir. Pradhan ve Chakraverty [11], kirişlerin farklı sınır şartları için farklı kayma deformasyon teorilerinin, serbest titreşim değerleri üzerindeki etkilerini incelemişlerdir. $\mathrm{Su}$ ve Banerjee [12], FD Timoshenko kirişlerin serbest titreşim frekanslarını, problemin dinamik rijitlik matrisini elde ederek araştırmışlardır. Hareketin 
diferansiyel denklemleri çözülmüş ve eksenel kuvvet, kayma kuvveti ve eğilme momenti için ifadeler türetilmiştir. Jing ve arkadaşları [13], FD malzemeli kirişlerin statik ve serbest titreşim davranışını analiz etmek için merkezi sonlu hacim yöntemi ve Timoshenko kiriş teorisi kombinasyonuna dayanan yeni bir yaklaşım geliştirmişlerdir. Düzgün yayılı yük altında FD kiriş için, Hamilton prensibi kullanılarak, genel dinamik denklemleri türetilmiştir. Bu denklemler, statik eğilme problemi veya serbest titreşim problemi için basitleştirilmiştir. Avcar ve Alwan [14], Rayleigh kiriş teorisini kullanarak sabit mesnetli FD kirişin serbest titreşim analizini yapmışlardır. Lee ve Lee [15], Euler-Bernoulli kirişlerinin serbest titreşim davranışlarını transfer matris metoduyla incelemişlerdir. Yazarlar, kirişin iki ucunda sınır şartları arasında bir ilişki kurarak FD malzemeli kiriş için kesin transfer matrisini elde etmişlerdir. Malzeme özelliklerinin yükseklik boyunca kuvvet fonksiyonu şeklinde değiştiği durumlarda, problemin doğal frekansları ve mod şekillerinin hesabında bu metodun gayet kullanışlı olduğunu ifade etmişlerdir. Kahya ve Turan [16], FD kirişlerin serbest titreşim ve burkulma analizleri için birinci mertebe kiriş teorisine dayanan, beş düğüm noktalı ve on serbestlik dereceli bir sonlu eleman önermişlerdir. Turan ve Kahya [17] çalışmalarında, birinci mertebe kayma deformasyonu teorisine dayalı olarak FD kirişlerin doğal frekanslarını Navier çözüm yöntemi ile elde etmişlerdir. Hareket denklemlerini Lagrange eşitlikleri ile türetmiş, problemin çözümünde ise trigonometrik fonksiyonları kullanmışlardır.

Banerjee ve Ananthapuvirajah [18], FD kirişlerin veya çerçevelerin serbest titreşim analizi için dinamik rijitlik matrisi yöntemini uygulamıştır. Dinamik rijitlik matrisinde kuvvetlerin genliklerini kirişin iki ucundaki yer değiştirmeler ile ilişkilendirilerek formüle etmişler ve çözüm için Wittrick-Williams algoritmasını kullanmışlardır. Çelebi ve arkadaşları [19], düzlemsel elastisite teorisine ait hareket denklemlerini kullanarak, basit mesnetli FD yüksek kirişlerin serbest titreşim frekanslarını hesaplamışlardır. Çalışmada, denklemleri daha basit hale getirmek için değişkenlere ayırmışlar ve hareket denklemlerinin TFY yardımıyla çözümüne olanak sağlamışlardır.
Yapılan araştırmalara göre, doğru eksenli kirişlerin çeşitli statik ve dinamik yüklemeler altındaki çözümlerinin birçok farklı yöntemle ele alındı $\breve{g ̆}_{1}$ görülmüştür. Yazarların bilgisine göre, kalınlık boyunca FD malzemeli, doğru eksenli Timoshenko kirişlerinin serbest titreşim davranışını TFY ile inceleyen herhangi bir çalışmaya rastlanılmamıştır. $\mathrm{Bu}$ tür kirişlerin serbest titreşim davranışları, ilk defa bu çalışmada TFY ile analiz edilmiştir. FD çubukların serbest titreşim davranışını idare eden kanonik denklemler birinci mertebe kayma deformasyon teorisine dayalı minimum toplam enerji prensibi ile elde edilmiştir. Timoshenko kirişlerinin doğal titreşim frekanslarını hesaplamak için Fortran dilinde bir bilgisayar programı yazılmıştır. $\mathrm{Bu}$ çalışmada malzeme değişim katsayısının, farklı sınır koşullarının ve kiriş boykalınlık oranlarının serbest titreşim frekansları üzerindeki etkileri detaylı bir şekilde araştırılmıştır.

$\mathrm{Bu}$ çalışmanın temel amacı, kalınlık boyunca FD malzemeli Timoshenko kirişlerinin beklenen davranışını belirlemekle birlikte, bu metodun etkin ve kolayca uygulanabilirliğini de göstermektir.

\section{MATERYAL VE METOT}

Şekil 1'de görülen düz eksenli FD kirişin elastisite modülü, $E(z)$ ve kütlesel yoğunluğu, $\rho(z)$ 'nin kiriş kalınlığı boyunca üstel olarak değiştiği kabulü yapılmıştır. Dolayısıyla malzeme özellikleri, $z$ koordinatının fonksiyonlarıdır. Malzeme değişim fonksiyonu Eşitlik 1'de verilmektedir.

$$
P(z)=\left(P_{t}-P_{b}\right)\left(\frac{z}{h}+\frac{l}{2}\right)^{n_{z}}-P_{b}
$$

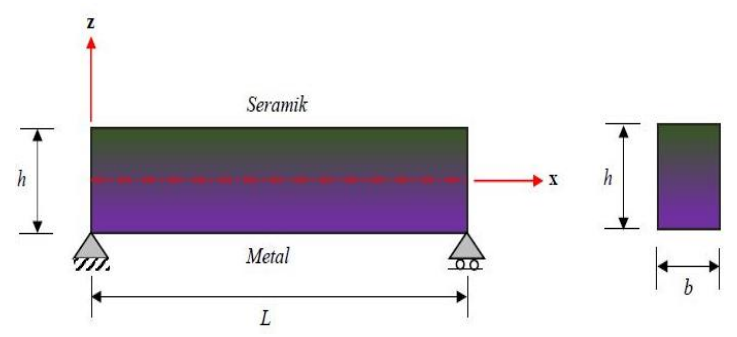

Şekil 1. FD malzemeli kiriş ve enkesiti 
Burada $P(z)$, malzeme özelliklerini ifade etmektedir. $n_{z}$ ise, malzemeye ait hacim oranının kiriș kalınlığ 1 boyunca dağılımını belirleyen malzeme değişim katsayısıdır. Timoshenko kiriş teorisine göre $U_{x}$ ve $U_{z}$ eksenel ve düşey yer değiştirmeleri, $\varepsilon_{x}, x$ doğrultusundaki eksenel, $\gamma_{x z}$ ise açisal şekil değiştirmeleri göstermekte olup, Eşitlik 2, 3, ve 4'te verilmektedir.

$U_{x}=u(x, t)+z \theta(x, t) ; U_{z}=w(x, t)$

$\varepsilon_{x}=\frac{\partial U_{x}}{\partial x}=u^{\prime}+z \theta^{\prime}$

$\gamma_{x z}=\theta+w^{\prime}$

İç kuvvetler ve gerilmeler arasındaki ilişki Eşitlik 5, 6 ve 7'deki gibi verilmektedir.

$N_{x}=b \int_{-h / 2}^{+h / 2} \sigma_{x} d z=b \int_{-h / 2}^{+h / 2} E(x, z)\left(\varepsilon_{x}\right) d z$

$M_{x}=b \int_{-h / 2}^{+h / 2} \sigma_{x} z d z=b \int_{-h / 2}^{+h / 2} E(x, z)\left(\varepsilon_{x}\right) z d z$

$Q_{z}=b \int_{-h / 2}^{+h / 2} k_{s} \tau_{x z} d z=b \int_{-h / 2}^{+h / 2} k_{s} \frac{E(x, z)}{2(1+v)} \gamma_{x z} d z$

Yukarıdaki denklemlerde verilen kesit tesirlerinin açılımı ise Eşitlik 8, 9 ve 10'da gösterilmiştir.

$N_{x}=b\left(A_{11} u^{\prime}+A_{12} \theta^{\prime}\right)$

$Q_{z}=b A_{33}\left(\theta+w^{\prime}\right)$

$M_{x}=b\left(A_{12} u^{\prime}+A_{22} \theta^{\prime}\right)$

Burada $A_{11}, A_{12}, A_{22}$ ve $A_{33}$ kesit rijitlik sabitlerini ifade etmekte olup, aşağıda verilmiştir.

$A_{11}=\int_{-h / 2}^{+h / 2} E(x, z) d z$

$$
\begin{aligned}
& A_{12}=\int_{-h / 2}^{+h / 2} E(x, z) z d z \\
& A_{22}=\int_{-h / 2}^{+h / 2} E(x, z) z^{2} d z
\end{aligned}
$$

$A_{33}=k_{s} \int_{-h / 2}^{+h / 2} \frac{E(x, z)}{2(1+v)} d z$

FD çubuklar için kinetik enerji ve toplam potansiyel enerji ifadeleri, 15 ve 16 integralleri ile bulunmaktadır.

$\Pi_{t}=\int_{0}^{l} \int_{A} \frac{1}{2}\left(\sigma_{x} \varepsilon_{x}+\tau_{x z} \gamma_{x z}\right) d A d x$

$T=\frac{1}{2} \int_{0}^{l} \int_{A} \rho(x, z)\left(\dot{U}_{x}^{2}+\dot{U}_{z}^{2}\right) d A d x$

Burada $\rho$, kütlesel yoğunluğu, $\dot{U}_{x}$ ve $\dot{U}_{z}$ ise sırasıyla, kiriş üzerindeki bir noktanın hızının $x$ (boyuna) ve $z$ (düşey) bileşenleridir.

Kinetik enerjiden ve potansiyel enerjiyi çıkararak Sistemin Langrangian'1 elde edilmektedir.

$$
\begin{gathered}
L=T-\Pi_{t} \\
L=l b \int_{-h / 2}^{h / 2} \frac{1}{2} \rho(x, z)\left(\dot{u}^{2}+2 z \dot{u} \dot{\theta}+\dot{\theta}^{2} z^{2}+\dot{w}^{2}\right) \\
-\left[\frac{1}{2}\left(\sigma_{x} \varepsilon_{x}+\tau_{x z} \gamma_{x z}\right)\right] d z
\end{gathered}
$$

Hamilton Prensibi ise, Lagrangian'ın zamana göre integralinin varyasyonunu sifır yapan varsayımdır.

$\delta \int_{t 0}^{t l} L d t=0$

Gerekli büyüklüklerin impulsif bileșenleri ve türevleri teşkil edilerek, FD malzemeli doğru eksenli kirişlere ait kısmi diferansiyel denklemler (19-24) elde edilmiştir. Burada $I_{0}, I_{1}$ ve $I_{2}$, kütlesel atalet momentleridir. 
$\frac{\partial u}{\partial x}=\frac{A_{12} M_{x}-A_{22} N_{x}}{b\left(A_{12}{ }^{2}-A_{11} A_{22}\right)}$

$\frac{\partial w}{\partial x}=\frac{Q_{z}}{b k_{s} A_{33}}-\theta$

$\frac{\partial \theta}{\partial x}=\frac{-A_{11} M_{x}+A_{12} N_{x}}{b\left(A_{12}^{2}-A_{11} A_{22}\right)}$

$\frac{\partial N_{x}}{\partial x}=I_{0} \frac{\partial^{2} u}{\partial t^{2}}+I_{1} \frac{\partial^{2} \theta}{\partial t^{2}}$

$\frac{\partial Q_{z}}{\partial x}=I_{0} \frac{\partial^{2} w}{\partial t^{2}}$

$\frac{\partial M_{z}}{\partial x}=Q_{z}+I_{1} \frac{\partial^{2} u}{\partial t^{2}}+I_{2} \frac{\partial^{2} \theta}{\partial t^{2}}$

Sistem hareket eşitliklerinin (19-24) Laplace dönüşümü alınırsa, kısmi diferansiyel denklemler dönüşmüş uzayda adi diferansiyel denklem takımı haline dönüşmektedir. Böylece, Laplace uzayında FD çubukların davranışını idare eden adi diferansiyel denklem takımı, kanonik formda aşağıdaki gibi elde edilmektedir.

$\frac{d \bar{u}}{d x}=\frac{A_{12} \bar{M}_{x}-A_{22} \bar{N}_{x}}{b\left(A_{12}{ }^{2}-A_{11} A_{22}\right)}$

$\frac{d \bar{w}}{d x}=\frac{\bar{Q}_{z}}{b k_{s} A_{33}}-\bar{\theta}$

$\frac{d \bar{\theta}}{d x}=\frac{-A_{11} \bar{M}_{x}+A_{12} \bar{N}_{x}}{b\left(A_{12}{ }^{2}-A_{11} A_{22}\right)}$

$\frac{d \bar{N}_{x}}{d x}=I_{0} s^{2} \bar{u}+I_{l} s^{2} \bar{\theta}$

$\frac{d \bar{Q}_{z}}{d x}=I_{0} s^{2} \bar{w}$

$\frac{d \bar{M}_{x}}{d x}=\bar{Q}_{z}+I_{1} s^{2} \bar{u}+I_{2} s^{2} \bar{\theta}$

Burada $\left(^{-}\right)$ile gösterilen ifadeler büyüklüklerin Laplace Dönüşümünü göstermektedir. $s$, Laplace parametresi olup, kompleks bir sayıdır. Serbest titreşim analizleri için Laplace parametresi ' $s$ ',

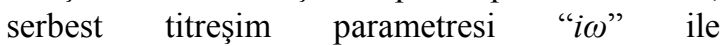
değiştirilmiştir. (25-30) eşitlikleri aşağıdaki gibi matris formunda yazılabilir.

$\frac{d\{\mathbf{Y}(x, \omega)\}}{d x}=\mathbf{F}(x, \omega) \mathbf{Y}^{*}(x)$

Burada $x$, bağımsız değişkendir. TFY, başlangıç şartları yardımı ile Eşitlik 31 çözümüne dayanmaktadır. Bu yöntem ile sınır değer problemi başlangıç değer problemine indirgenmektedir. Denklem 31'in genel çözümü,

$\{\mathbf{Y}(x, \omega)\}=\sum_{\mathrm{m}=1}^{6} C_{m}\left[\mathbf{U}^{(\mathrm{m})}(x, \omega)\right]$

Burada $C_{m}$, integrasyon sabitleri sınır şartlarından elde edilmektedir. Bu sabitler elde edilirken sınır şartları kullanılarak bir takım denklemler oluşturulur ve katsayılar matris formunda yazılır. Böylece katsayılar matrisinin determinantını sıfır yapan değerler serbest titreşim frekanslarını vermektedir. TFY ile sistemin kütle ve rijitlik matrisleri ayrı ayrı elde edilemediğinden, problemin öz vektörleri hesaplanmamaktadır.

Bunun yanı sıra, bu çalışmada önerilen yaklaşım Eşitlik 1 ile verilen malzeme değişim fonksiyonu ile sınırlı olmayıp, çeşitli malzeme değişim modelleri için de kolayca uygulanabilmektedir.

\section{SAYISAL UYGULAMALAR}

$\mathrm{Bu}$ çalışmada, çeşitli malzeme derecelenme indisi ve farklı boy-kalınlık $(L / h)$ oranları için farklı sınır şartlarına sahip FD kirişlerin boyutsuz serbest titreşim frekansları hesaplanmıştır. Çözümler için Fortran dilinde bir bilgisayar programı hazırlanmıştır. TFY'ne dayalı başlangıç değer probleminin çözümü için 5. Mertebe Runge-Kutta (RK5) algoritması kullanılmıştır [20-21].

Çözümlerde Çizelge 1'de verilen malzeme sabitleri kullanılmıştır. 
Çizelge 1. Malzemelerin mekanik özellikleri

\begin{tabular}{|l|c|c|}
\hline Malzeme & $\boldsymbol{E}(\mathbf{G p a})$ & $\boldsymbol{\rho}\left(\mathbf{k g} / \mathbf{m}^{\mathbf{3}}\right)$ \\
\hline Alüminyum $\left(\boldsymbol{P}_{\boldsymbol{b}}\right)$ & 70 & 2702 \\
\hline Seramik $\left(\boldsymbol{P}_{\boldsymbol{t}}\right)$ & 380 & 3960 \\
\hline
\end{tabular}

Ele alınan FD kirişe ait geometrik özellikler şöyledir: kesit genişliği $0,1 \mathrm{~m}$, yüksekliği $0,1 \mathrm{~m}$ ve kayma düzeltme faktörü 5/6 olarak alınmıştır.

Hesaplanan frekans değeri aşağıdaki ifade ile boyutsuz hale getirilmiştir.

$$
\lambda=\frac{\omega L^{2}}{h} \sqrt{\frac{\rho_{b}}{E_{b}}}
$$

$\mathrm{Bu}$ çalışmada, ilk olarak farklı boy/kalınlık oranları için ankastre-ankastre sınır şartlarına sahip FD kirişin boyutsuz frekansları elde edilmiştir. Bu çalışmada bulunan sonuçlar ve literatürde verilen değerler Çizelge 2'de karşılaştırılmıştır. Çizelge incelendiğinde, FD malzemeli kirişler için bu çalışmada elde edilen boyutsuz serbest titreşim frekanslarının literatürde verilen boyutsuz frekanslar ile uyum içerisinde olduğu görülmüştür.

Çizelge 2. Boyutsuz frekans değerleri

\begin{tabular}{|c|c|c|c|c|c|}
\hline & \multicolumn{2}{|c|}{$L / h=5$} & \multicolumn{2}{|c|}{$L / h=20$} \\
\hline & & Li [2] & Bu çalışma & $\operatorname{Li}[2]$ & Bu çalışma \\
\hline \multirow{2}{*}{$\approx$} & 1 & 4,266 & 4,255 & 4,517 & 4,502 \\
\hline & 5 & 3,754 & 3,744 & 4,023 & 4,009 \\
\hline
\end{tabular}

Farklı sınır şartlarının ve farklı boy-kalınlık $(L / h)$ oranlarının FD kirişlerin frekansları üzerindeki etkilerini araştırmak için parametrik çalışmalar yapılmıştır. Ankastre-Ankastre (A-A), Sabit-Sabit (S-S), Ankastre-Sabit (A-S), ve Ankastre-Serbest (A-Se) sınır şartlarına sahip kirişler için ilk beş boyutsuz frekans değerleri hesaplanmış ve sırasıyla Çizelge (3-6)'da verilmektedir.

Çizelge 3. Ankastre-Ankastre sınır şartlarına ait boyutsuz frekans değerleri

\begin{tabular}{|c|c|c|c|r|r|}
\hline & & \multicolumn{4}{|c|}{$\boldsymbol{n}_{z}$} \\
\hline $\boldsymbol{L} / \boldsymbol{h}$ & Mod & $\mathbf{0}$ (Seramik) & $\mathbf{1}$ & $\mathbf{5}$ & (Metal) \\
\hline \multirow{5}{*}{5} & $\mathbf{1}$ & 9,9975 & 7,9001 & 6,6425 & 5,1946 \\
\cline { 2 - 6 } & $\mathbf{2}$ & 22,8843 & 18,3024 & 15,0799 & 11,8905 \\
\cline { 2 - 6 } & $\mathbf{3}$ & 30,2314 & 25,2962 & 19,8529 & 15,7080 \\
\cline { 2 - 6 } & $\mathbf{4}$ & 38,1387 & 30,7064 & 25,0468 & 19,8165 \\
\cline { 2 - 6 } & $\mathbf{5}$ & 54,4934 & 44,0746 & 35,7270 & 28,3143 \\
\hline
\end{tabular}

\begin{tabular}{|c|c|c|c|c|c|}
\hline \multirow{4}{*}{$\mathbf{2 0}$} & $\mathbf{1}$ & 12,2201 & 9,4297 & 8,1682 & 6,3495 \\
\cline { 2 - 6 } & $\mathbf{2}$ & 32,9705 & 25,5056 & 22,0119 & 17,1312 \\
\cline { 2 - 6 } & $\mathbf{3}$ & 62,8988 & 48,7987 & 41,9286 & 32,6817 \\
\cline { 2 - 6 } & $\mathbf{4}$ & 100,6726 & 78,3502 & 66,9873 & 52,3086 \\
\cline { 2 - 6 } & $\mathbf{5}$ & 120,9255 & 101,4368 & 79,8102 & 62,8319 \\
\hline
\end{tabular}

Çizelge 4. Sabit-sabit sınır şartlarına ait boyutsuz frekans değerleri

\begin{tabular}{|c|c|c|c|c|r|}
\hline \multicolumn{2}{|c|}{} & \multicolumn{5}{|c|}{$\boldsymbol{n}_{z}$} \\
\hline $\boldsymbol{L} / \boldsymbol{h}$ & Mod & $\mathbf{0}$ (Seramik) & $\mathbf{1}$ & $\mathbf{5}$ & (Metal) \\
\hline \multirow{5}{*}{$\mathbf{5}$} & $\mathbf{1}$ & 5,1525 & 4,2550 & 3,7443 & 2,6772 \\
\cline { 2 - 6 } & $\mathbf{2}$ & 17,8711 & 13,7665 & 11,4730 & 9,2857 \\
\cline { 2 - 7 } & $\mathbf{3}$ & 30,2314 & 24,8023 & 19,4259 & 15,7080 \\
\cline { 2 - 7 } & $\mathbf{4}$ & 34,1449 & 27,0207 & 22,3860 & 17,7414 \\
\cline { 2 - 7 } & $\mathbf{5}$ & 51,8131 & 41,6357 & 34,1676 & 26,9217 \\
\hline \multirow{5}{*}{$\mathbf{2 0}$} & $\mathbf{1}$ & 5,4603 & 4,5024 & 4,0092 & 2,8371 \\
\cline { 2 - 7 } & $\mathbf{2}$ & 21,5732 & 16,6140 & 14,3803 & 11,2092 \\
\cline { 2 - 6 } & $\mathbf{3}$ & 47,5921 & 37,0334 & 32,0637 & 24,7285 \\
\cline { 2 - 6 } & $\mathbf{4}$ & 82,4397 & 63,4079 & 54,1806 & 42,8350 \\
\cline { 2 - 7 } & $\mathbf{5}$ & 120,9255 & 97,0143 & 78,6711 & 62,8319 \\
\hline
\end{tabular}

Çizelge 5. Ankastre-sabit sınır şartlarına ait boyutsuz frekans değerleri

\begin{tabular}{|c|c|c|c|c|r|}
\hline \multicolumn{2}{|c|}{} & \multicolumn{4}{|c|}{$\boldsymbol{n}_{z}$} \\
\hline $\boldsymbol{L} / \boldsymbol{h}$ & Mod & 0 (Seramik) & $\mathbf{1}$ & $\mathbf{5}$ & (Metal) \\
\hline \multirow{5}{*}{5} & $\mathbf{1}$ & 7,4652 & 5,9047 & 5,0414 & 3,8788 \\
\cline { 2 - 6 } & $\mathbf{2}$ & 20,4884 & 16,1541 & 13,3985 & 10,6456 \\
\cline { 2 - 6 } & $\mathbf{3}$ & 30,2314 & 24,9074 & 19,5371 & 15,7080 \\
\cline { 2 - 6 } & $\mathbf{4}$ & 36,2214 & 29,0911 & 23,8821 & 18,8203 \\
\cline { 2 - 6 } & $\mathbf{5}$ & 53,2075 & 42,8104 & 34,8866 & 27,6462 \\
\hline \multirow{4}{*}{$\mathbf{2 0}$} & $\mathbf{1}$ & 8,4814 & 6,6185 & 5,7693 & 4,4068 \\
\cline { 2 - 6 } & $\mathbf{2}$ & 27,0276 & 20,9361 & 18,1251 & 14,0433 \\
\cline { 2 - 6 } & $\mathbf{3}$ & 55,0737 & 42,6640 & 36,7500 & 28,6159 \\
\cline { 2 - 6 } & $\mathbf{4}$ & 91,4633 & 70,8796 & 60,6328 & 47,5236 \\
\cline { 2 - 6 } & $\mathbf{5}$ & 120,9255 & 99,7341 & 78,8275 & 62,8319 \\
\hline
\end{tabular}

Çizelge 6. Ankastre-Serbest sınır şartlarına ait boyutsuz frekans değerleri

\begin{tabular}{|c|c|c|r|r|r|}
\hline \multicolumn{2}{|c|}{} & \multicolumn{4}{|c|}{$\boldsymbol{n}_{z}$} \\
\hline $\boldsymbol{L} / \boldsymbol{h}$ & Mod & $\mathbf{0}$ (Seramik) & $\mathbf{1}$ & $\mathbf{5}$ & (Metal) \\
\hline \multirow{4}{*}{$\mathbf{5}$} & $\mathbf{1}$ & 1,8944 & 1,4628 & 1,2643 & 0,9843 \\
\cline { 2 - 6 } & $\mathbf{2}$ & 10,2025 & 7,9720 & 6,7245 & 5,3011 \\
\cline { 2 - 6 } & $\mathbf{3}$ & 15,1157 & 12,7061 & 10,0311 & 7,8540 \\
\cline { 2 - 6 } & $\mathbf{4}$ & 24,2839 & 19,1882 & 15,9506 & 12,6177 \\
\cline { 2 - 6 } & $\mathbf{5}$ & 40,3168 & 32,1235 & 26,3757 & 20,9483 \\
\hline \multirow{4}{*}{$\mathbf{2 0}$} & $\mathbf{1}$ & 1,9495 & 1,5011 & 1,3039 & 1,0130 \\
\cline { 2 - 6 } & $\mathbf{2}$ & 12,0753 & 9,3087 & 8,0687 & 6,2742 \\
\cline { 2 - 6 } & $\mathbf{3}$ & 33,2016 & 25,6401 & 22,1548 & 17,2513 \\
\cline { 2 - 6 } & $\mathbf{4}$ & 60,4627 & 49,0520 & 39,8691 & 31,4159 \\
\cline { 2 - 6 } & $\mathbf{5}$ & 63,4443 & 50,7989 & 42,3371 & 32,9651 \\
\hline
\end{tabular}

Çizelgeler incelendiğinde, en büyük doğal frekanslarının, $n_{z}=0$ için, yani kirişin seramik olması durumunda ortaya çıktığ $1, n_{z}$ arttıkça doğal frekansların azaldığı görülmektedir. Farklı sınır 
şartlarına ait çizelgeler incelendiğinde, ilk olarak tüm mesnet türlerinde $L / h$ oranı arttıkça frekans değerlerinin arttığı görülmüştür. En büyük boyutsuz doğal titreşim frekans değeri A-A mesnet türünde, en küçük frekans değeri ise A-Se kirişinde görülmüştür.

\section{SONUÇLAR}

$\mathrm{Bu}$ araştırmada, kalınlık boyunca FD malzemeli çubukların birinci mertebe kayma deformasyon teorisine dayalı serbest titreşim analizleri yapılmıştır. Frekans uzayında elde edilen adi diferansiyel denklemler, TFY'ne dayalı başlangıç değer probleminin çözümleri için RK5 algoritması kullanılmıştır. Ele alınan problem, önerilen yöntem ile çözülmüş ve sonuçlar ile karşılaştırılmıştır. Elde edilen değerlerin bir birleri ile uyum içerisinde oldukları görülmüştür. Ayrıca, malzeme değişim katsayısının, farklı sınır şartlarının ve farklı boy-kalınlık oranlarının probleminin doğal titreşim frekanslarını önemli ölçüde etkilediği gözlemlenmiştir.

Tekrar belirtmek gerekirse sunulan yaklaşımda, bu çalışmada kullanılan malzeme modeli yerine, istenirse farklı malzeme modelleri de kolayca uygulanabilmektedir. Bu çalışmanın temel amacı, kalınlık boyunca FD malzemeli düz eksenli Timoshenko kirişlerinin beklenen davranışını teyit etmekle beraber, bu metodun etkin ve kolayca uygulanabilirliğini de göstermektir.

\section{KAYNAKLAR}

1. Aydoğdu, M., Taşkın, V., 2007. Free Vibration Analysis of Functionally Graded Beams with Simply Supported Edges. Materials \& Design, 28(5), 1651-1656.

2. Li, X.F., 2008. A Unified Approach for Analyzing Static and Dynamic Behaviors of Functionally Graded Timoshenko and Eulerbernoulli Beams. Journal of Sound and Vibrations, 318, 1210-1229.

3. Sina, S.A., Navazi, H.M., Haddadpour, H., 2009. An Analytical Method for Free Vibration Analysis of Functionally Graded Beams. Materials and Design, 30(3), 741-747.
4. Şimşek, M., 2010. Vibration Analysis of a Functionally Graded Beam Under a Moving Mass by Using Different Beam Theories. Composite Structures, 92, 904-917.

5. Alshorbagy, A.E., Eltaher, M.A., ve Mahmoud, F.F., 2011. Free Vibration Characteristics of a Functionally Graded Beam by Finite Element Method. Applied Mathematical Modelling, 35, 412-425.

6. Anandrao, K.S., Gupta, R.K., Ramachandran, P., Rao, G.V., 2012. Free Vibration Analysis of Functionally Graded Beams. Defence Science Journal, 62(3), 139-146.

7. Thai, H.T., Vo, T.P., 2012. Bending and Free Vibration of Functionally Graded Beams Using Various Higher-order Shear Deformation Beam Theories. International Journal of Mechanical Sciences, 62(1), 57-66.

8. Pradhan, K.K., Chakraverty, S., 2013. Free Vibration of Euler and Timoshenko Functionally Graded Beams by Rayleigh-ritz Method. Composites: Part B, 51, 175-184.

9. Nguyen, T.K., Vo, T.P., Thai, H.T., 2013. Static and Free Vibration of Axially Loaded Functionally Graded Beams Based on the Firstorder Shear Deformation Theory. Composites: Part B, 55, 147-157.

10.Su, H., Banerjee, J.R., Cheung, C.W., 2013. Dynamic Stiffness Formulation and Free Vibration Analysis of Functionally Graded Beams. Composite Structures 106, 854-862.

11. Pradhan, K.K., Chakraverty, S., 2014. Effects of Different Shear Deformation Theories on Free Vibration of Functionally Graded Beams. International Journal of Mechanical Sciences, 82, 149-160.

12. Su, H., Banerjee, J.R., 2015. Development of Dynamic Stiffness Method for Free Vibration of Functionally Graded Timoshenko Beams. Computers and Structures 147, 107-116.

13. Jing, L.L., Ming, P.J., Zhang, W.P., Fu, L.R., Cao, Y.P., 2016. Static and Free Vibration Analysis of Functionally Graded Beams by Combination Timoshenko Theory and Finite Volume Method. Composite Structures, 138, 192-213.

14. Avcar, M., Alwan, H.H.A., 2017. Free Vibration of Functionally Graded Rayleigh 
Beam. International Journal of Engineering \& Applied Sciences (IJEAS), 9(2), 127-137.

15. Lee, J.W., Lee, J.Y., 2017. Free Vibration Analysis of Functionally Graded Bernoullieuler Beams Using an Exact Transfer Matrix Expression. International Journal of Mechanical Sciences, 122, 1-17.

16. Kahya, V., Turan, M., 2017. Finite Element Model for Vibration and Buckling of Functionally Graded Beams Based on the Firstorder Shear Deformation Theory. Composites Part B: Engineering, 109, 108-115.

17. Turan, M., Kahya, V., 2018. Fonksiyonel Derecelendirilmiş Kirişlerin Serbest Titreşim Analizi. Karadeniz Fen Bilimleri Dergisi, 8(2), 119-130, DOI: $10.31466 / \mathrm{kfbd} .453833$

18. Banerjee, J.R., Ananthapuvirajah, A,. 2018. Free Vibration of Functionally Graded Beams and Frameworks Using the Dynamic Stiffness Method. Journal of Sound and Vibration, 422, 34-47.

19. Çelebi, K., Yarımpabuç, D., Tütüncü, N., 2018. Free Vibration Analysis of Functionally Graded Beams Using Complementary Functions Method. Arch. Appl. Mech., 88(5), 729-739.

20. Aslan, T.A., Noori, A.R., Temel, B., 2018. Dynamic Response of Viscoelastic Tapered Cycloidal Rods. Mechanics Research Communications, 92, 8-14.

21. Noori, A.R., Aslan, T.A., Temel B., 2018. An Efficient Approach for In-plane Free and Forced Vibrations of Axially Functionally Graded Parabolic Arches With Nonuniform Cross Section. Composite Structures, 200(15), 701-710. 